\title{
Immobilization hypercalcaemia due to low bone formation and responding to intravenous sodium sulphate
}

\author{
Richard A. Evans ${ }^{2}$, Peter J. Lawrence ${ }^{1}$, Govindasamy Thanakrishnan ${ }^{1}$, Ellen Hills ${ }^{2}$, \\ Stanley Y.P. Wong ${ }^{2}$ and Colin R. Dunstan ${ }^{2}$ \\ ${ }^{1}$ Intensive Care Unit and ${ }^{2}$ Metabolic Unit, Concord Hospital, Sydney, NSW 2139, Australia
}

\begin{abstract}
Summary: A young man developed acute renal failure and hypercalcaemia following severe burns. The hypercalcaemia was initially controlled by haemodialysis, but it persisted after return of renal function. Plasma PTH was inappropriately elevated, but the nephrogenous cyclic adenosine monophosphate level was low; thus the PTH was probably not biologically active, and may have been artefactually elevated by the moderate renal impairment. Bone histology, showed a normal resorbing surface, but a zero forming surface, implying that the bone dissolution leading to hypercalcaemia resulted from a failure of bone formation. Because of widespread infection and impaired renal function, the hypercalcaemia could not be treated by corticosteroid drugs, mithramycin or phosphate, and there was no response to salmon calcitonin. He was therefore treated with intravenous sodium sulphate, which increased urinary calcium excretion and reduced the plasma calcium. Sodium sulphate still has a role in the treatment of patients with hypercalcaemia.
\end{abstract}

\section{Introduction}

Immobilization leads to bone atrophy and hence hypercalciuria. Hypercalcaemia can occur if the rate of bone loss is very rapid, or if renal excretion of calcium is impaired. The factors inducing bone loss are not well understood, and the elevated parathyroid hormone (PTH) levels observed in this condition do not appear to reflect increased PTH bioactivity (Evans et al., 1984).

In the patient reported here, severe immobilization hypercalcaemia did not respond to calcitonin, and other treatments were contraindicated by the clinical situation. He responded well to intravenous sodium sulphate, an agent which has been well studied in the past (Chakmakjian \& Bethune, 1966) but which is now little used.

\section{Case report}

A 21 year old male volunteer fire fighter was trapped in a bushfire, and suffered full thickness burns to $40 \%$ of his body, in addition to severe inhalation injury. He ws resuscitated by standard methods, which included endotracheal intubation and intravenous fluids. Rapidly progressive, extensive pneumonia was treated by antibiotics and respiratory support, including

Correspondence: R.A. Evans, M.B., B.S., F.R.A.C.P. Accepted: 25 September 1985 tracheostomy. On the sixteenth hospital day he developed septicaemia with hypotension and oliguric renal failure. He underwent peritoneal dialysis for 7 days, then haemodialysis for 65 days. He remained critically ill, with respiratory and renal failure and recurrent sepsis, for several months.

Hypercalcaemia was first apparent on day 48 , and was severe by day 72 (Figure 1). It was treated at first by omitting calcium from the dialysate. Because the serum testosterone level was low $(10.7 \mathrm{nmol} / 1$, normal range $13.5-40 \mathrm{nmol} / \mathrm{l})$, as expected during a severe illness, he was given two injections of testosterone esters (propionate $20 \mathrm{mg}$, phenylpropionate $40 \mathrm{mg}$, isocaproate $40 \mathrm{mg}$ ) in the hope of reducing bone resorption. However, it had no discernible effect. Salmon calcitonin 100 MRC U was given twice daily but the plasma calcium continued to rise. By day 75 renal function had returned and dialysis was carried out only to control the hypercalcaemia. The plasma did not change following the administration of 1 litre of $3 \%$ sodium chloride. The following day he was given 1 litre $3.9 \%$ sodium sulphate $(122 \mathrm{mmol} / \mathrm{l})$ and the plasma calcium fell by $0.27 \mathrm{mmol} / 1$. Intravenous sodium sulphate was then given, usually in amounts of 2-3 litres/24 hours to maintain plasma calcium below $3.50 \mathrm{mmol} / \mathrm{l}$. Twelve infusions were given over the subsequent 50 days, with an average decrease in plasma calcium over 48 hours of $0.38 \mathrm{mmol} / 1$, and a concomitant increase in urinary calcium of $9 \mathrm{mmol} / 24$ 


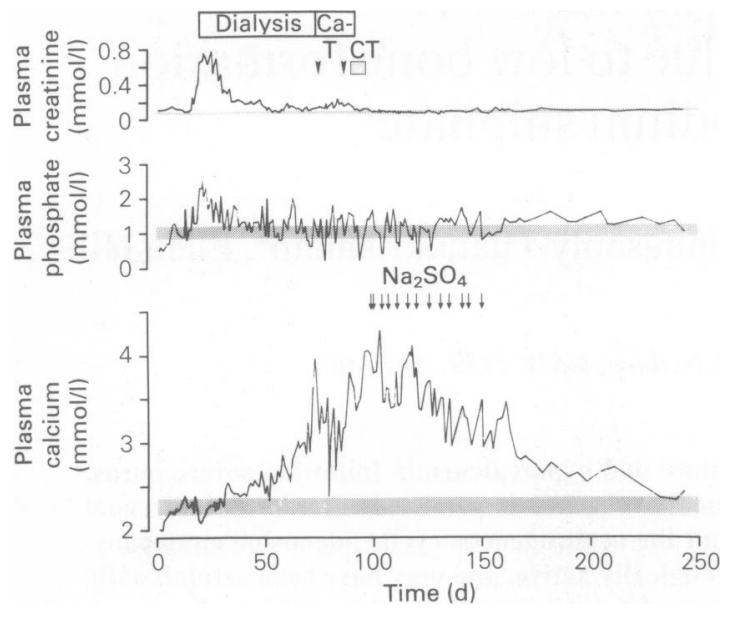

Figure 1 Major biochemical variables and therapeutic procedures. Plasma calcium level is corrected for albumin level. Normal ranges are shaded. ' $\mathrm{Ca}$-' in the dialysis block indicates the period of calcium-free dialysate. ' $T$ ' indicates the two testosterone injections, and the ' $C T$ ' block shows the duration of twice-daily calcitonin injections. Each arrow beneath ' $\mathrm{Na}_{2} \mathrm{SO}_{4}$ ' indicates a 3 litre infusion of $122 \mathrm{mmol} / 1$ sodium sulphate.

hours (increasing thus to a mean of $27 \mathrm{mmol} / 24$ hours). The plasma phosphate also decreased by a mean of $0.40 \mathrm{mmol} / 1$ following each infusion. The increase in urinary calcium was probably greater than recorded as, following the infusion, the urine contained finely particulate matter, presumably calcium sulphate, which not infrequently formed a paste and blocked the urinary catheter. Additional potassium was required during the infusion period because of increased urinary losses. Urinary hydroxyproline was measured on five occasions between day 103 and day 114 , and was $720 \pm 164$ (mean \pm s.d.) $\mu \mathrm{mol} / 24$ hours (normal $100-350 \mu \mathrm{mol} / 24$ hours).

After extensive skin grafting and other surgical procedures, mobilization commenced on day 160 , and the hypercalcaemia gradually subsided. The patient was discharged after 232 days in hospital.

\section{Metabolic study}

On day 125 , when the creatinine clearance was $43 \mathrm{ml} /$ minute, observations were made on plasma and urinary chemistry during a 1 litre infusion of sodium sulphate (Figure 2). There was a disproportionate decrease in plasma ionized calcium (Nova 2 ionized calcium analyser, normal range $1.12-1.32 \mathrm{mmol} / \mathrm{l}$ ) of $0.60 \mathrm{mmol} / 1 \mathrm{compared}$ to that in total calcium of
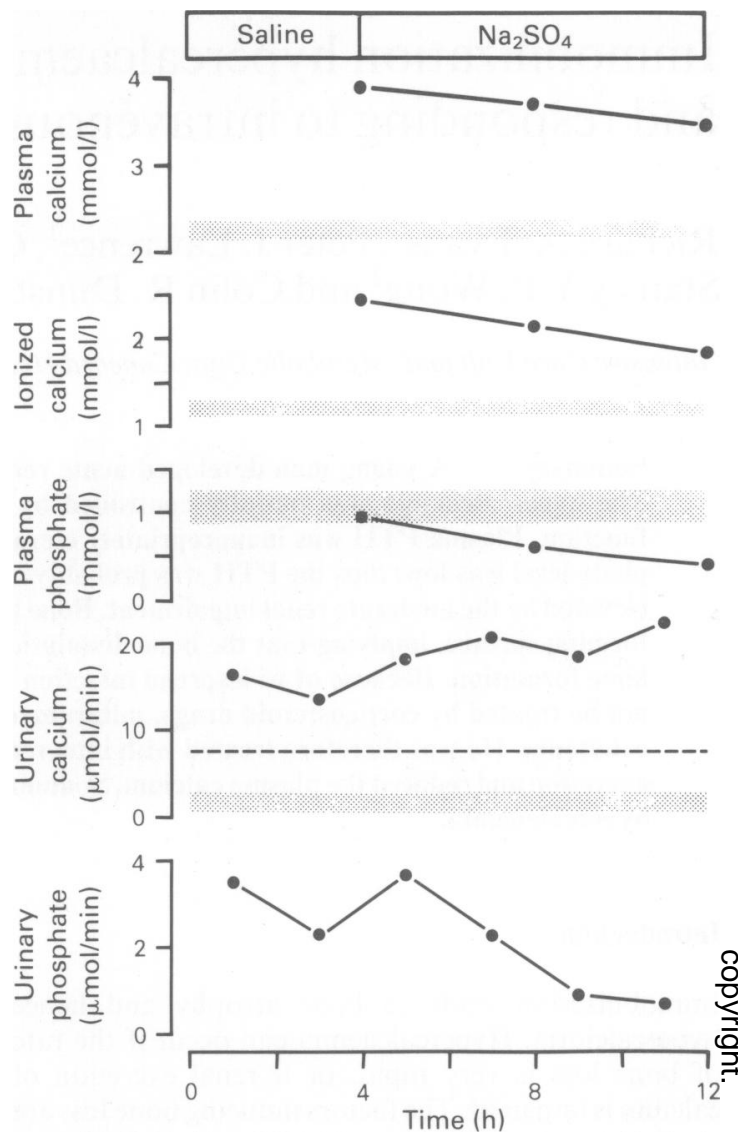

Figure 2 Changes in plasma and urine chemistry during an infusion of 1 litre $122 \mathrm{mmol}$ sodium sulphate. Normal ranges are shaded. For urinary calcium, the shaded area is for the fasting normal range, whilst the dotted line shows the upper limit of normal after oral administration of $1 \mathrm{~g}$ calcium.

$0.43 \mathrm{mmol} / 1$. Urinary calcium excretion increased, whilst there was a decrease in plasma calcium and phosphate levels, and in urinary phosphate. The serum PTH measured using a predominantly carboxyterminal specific antibody (Burroughs Wellcome AS 211-41, normal range $10-70 \mathrm{pmol} / \mathrm{ml})$ was slightly elevated at $79 \mathrm{pmol} / \mathrm{ml}$; a similar reading of $76 \mathrm{pmol} / \mathrm{ml}$ was obtained on day 104 . However, the urinary nephrogenous cyclic adenosine monophosphate excretion, measured by a competitive protein binding assay (Amersham International, normal range $0.3-2.8 \mathrm{nmol} / 100 \mathrm{ml}$ glomerular filtrate) was low at $0.56 \mathrm{nmol} / 100 \mathrm{ml}$ glomerular filtrate. 


\section{Bone scan}

A technetium-99m-pyrophosphate bone scan of the lower limbs was performed on day 205. It showed intense uptake of isotope by the metaphyseal regions (Figure 3).

\section{Bone biopsy}

This was taken from the posterior superior iliac spine with an $8 \mathrm{G}$ Jamshidi needle on day 69,3 days after administration of tetracycline hydrochloride $1.5 \mathrm{~g}$. Informed consent for the procedure was obtained, and the biopsy was taken during a general anaesthetic given to permit skin grafting. The sample was fixed in formalin, dehydrated in ethanol and embedded in a methyl methacrylate: glycol methacrylate medium (Dunstan \& Evans, 1980). Specific histochemical staining was used to identify osteoclasts and osteoblasts, and camera lucida tracings of these sections were quantitated using a digitizer interfaced to a computer. Histological data are shown in Table I. There was a normal osteoclast count and resorbing surface but no osteoblasts were recognizable, and the mineralizing (tetracycline) surface was near zero, reflecting failure of bone formation.

\section{Discussion}

The hypercalcaemia in this patient was clearly due to immobilization rather than to rhabdomyolysis, which is characterized initially by hypocalcaemia and hyperphosphataemia, and then by moderate hypercalcaemia and hyperphosphataemia, and by moderate hypercalcaemia during the early polyuric phase of recovery (Llach et al., 1981). The bone loss in our patient probably resulted from a failure of bone formation in the presence of normal resorption, a response similar to that observed in rats subjected to weightlessness (Morey \& Baylink, 1978). The appearances in the bone scan suggested that the bone was particularly active metabolically in the metaphyseal regions, probably because these areas are highly stressed areas of predominantly cancellous bone. The elevated urinary hydroxyproline levels cannot be taken as evidence of increased bone resorption in this patient, who had many other sites of collagen breakdown.

Intravenous sodium sulphate increased urinary calcium excretion and decreased plasma calcium in this patient, with no side effects other than occasional obstruction of the urinary catheter by calcium sulphate sludge. The increase in urinary calcium excretion was similar to that reported previously (Chakmakjian \& Bethune, 1966), and the smaller decrease in

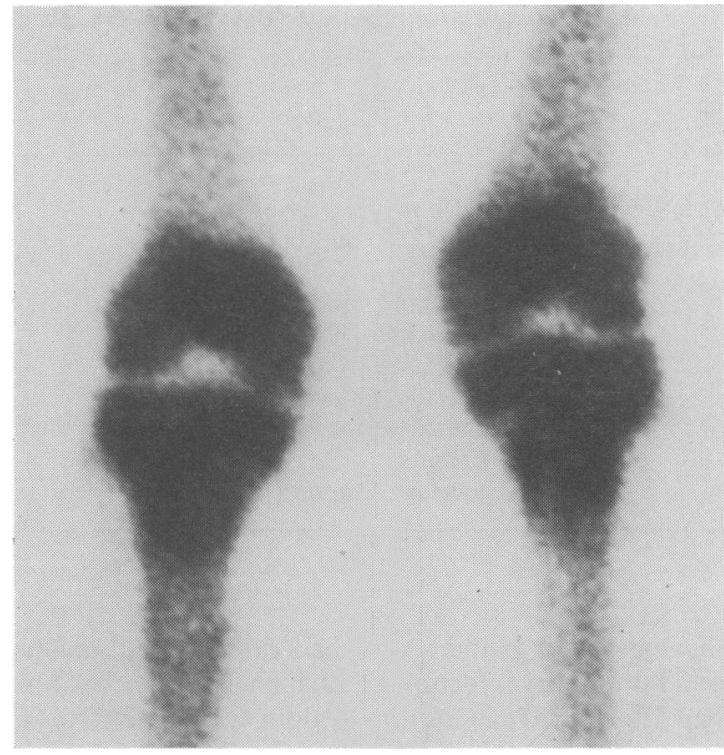

Figure 3 Technetium-99m-pyrophosphate bone scan showing intense uptake of isotope in periarticular and metaphyseal regions.

plasma calcium in our patient may have reflected unusually rapid bone atrophy. The increase in urinary calcium appears to result from binding of calcium by sulphate as a non-reabsorbable complex in the renal tubule (Walser \& Browder, 1959). The greater decrease in ionized than total calcium level following sulphate infusion in our patient is consistent with a recent suggestion (Friedlander et al., 1983) that such binding also occurs in the circulating blood. The infusion also contains considerable quantities of sodium, which increases urinary calcium excretion by competing with calcium for renal tubular reabsorption (Walser et al., 1959; Kleeman et al., 1964). However, sodium chloride induces a smaller increase in urinary calcium than did sodium sulphate (Chakmakjian \& Bethune, 1966), and did not reduce the plasma calcium level in our patient. Rehydration also reduces plasma calcium, but could not have contributed in our patient, whose hydration was carefully maintained in an intensive care ward.

Sodium sulphate was at one time a recommended treatment for hypercalcaemia (Lafferty, 1966; Patterson, 1974). Perhaps because of reports of the greater efficacy of phosphate, sulphate fell out of fashion, and is now rarely mentioned. Intravenous phosphate is still recommended, though it reduces urinary calcium and can lead to renal failure; it was clearly contraindicated in our patient, who already had renal impairment. Corticosteroids and mithramycin were also contrain- 
Table I Quantitative bone histology. Controls were six healthy hospital employees aged $32 \pm 8$ (mean \pm s.d.) years

\begin{tabular}{lcc}
\hline & Patient & $\begin{array}{c}\text { Control } \\
\text { (mean s.d.) }\end{array}$ \\
\hline $\begin{array}{l}\text { Areas } \\
\text { Total bone (\% section area) }\end{array}$ & 23 & $17 \pm 4$ \\
$\quad$ Osteoid (\% total bone) & 4.9 & $3.8 \pm 2.5$ \\
Surfaces & 1.4 & $14 \pm 7$ \\
$\quad$ Osteoid (\% bone surface) & 0.06 & $13 \pm 7$ \\
$\quad$ Tetracycline (\% total surface) & 0 & $5.6 \pm 2.7$ \\
Osteoblasts (\% total surface) & 1.2 & $7.2 \pm 3.2$ \\
$\quad$ Resorbing surface (\% total surface) & 24 & $1.0 \pm 0.5$ \\
$\quad$ Crenated surface (\% total surface) & 1.4 & 0.3 \\
Cell Count & & 1.2 \\
$\quad$ Osteoclasts (per mm ${ }^{2}$ section area) & & \\
\hline
\end{tabular}

dicated in our patient, who had extensive cutaneous and pulmonary infections, which on several occasions had threatened his life. Calcitonin was ineffective in the relatively small doses given. Combined oestrogen and testosterone therapy has been reported to be effective in a single patient (Mason, 1957) but the apparent effect may have been due to concurrent mobilization. Testosterone was not helpful in our patient. Intravenous diphosphonate drugs may not be used in Australia for the treatment of hypercalcaemia,

\section{References}

CHAKMAKJIAN, Z.H. \& BETHUNE, J.E. (1966). Sodium sulfate treatment of hypercalcemia. New England Journal of Medicine, 275, 862.

DUNSTAN, C.R. \& EVANS, R.A. (1980). Quantitative bone histology: a new method. Pathology, 12, 255.

EVANS, R.A., BRIDGEMAN, M., HILLS, E. \& DUNSTAN, C.R. (1984). Immobilisation hypercalcemia. Mineral and Electrolyte Metabolism, 10, 244.

FRIEDLANDER, M.A., LEMKE, J.H., JOHNSTON, M.J. \& FREEMAN, R.M. (1983). The effect of sulfate on serum ionized calcium. American Journal of Kidney Diseases, 2 , 660.

KLEEMAN, C.R., BOHANNAN, J., BERNSTEIN, D., LING, S. \& MAXWELL, M.H. (1964). Effect of variations in sodium intake on calcium excretion in normal humans. Proceedings of the Society for Experimental Biology and Medicine, unless it is due to malignant disease. Thus sodium sulphate is still a useful agent in some patients with hypercalcaemia.

\section{Acknowledgement}

We would like to acknowledge the support of the Department of Veterans' Affairs.

$115,29$.

LAFFERTY, F.W. (1966). Pseudohyperparathyroidism. Medicine, 45, 247.

LLACH, F., FELSENFELD, A.J. \& HAUSSLER, M. (1981). The pathophysiology of altered calcium metabolism in rhabdomyolysis-induced acute renal failure. New England Journal of Medicine, 305, 117.

MASON, A.S. (1957). Acute osteoporosis with hypercalcaemia. Lancet, i, 911.

MOREY, E.R. \& BAYLINK, D.J. (1978). Inhibition of bone formation during space flight. Science, 201, 1138.

PATERSON, C.R. (1974). Drugs for the treatment of hypercalcaemia. Postgraduate Medical Journal, 50, 158.

WALSER, M. \& BROWDER, A.A. (1959). Ion association. III The effect of sulfate infusion on calcium excretion. Journal of Clinical Investigation, 38, 1404. 